\title{
Resident and dispersal behavior among individuals within a population of American lobster Homarus americanus
}

\author{
Heather D. Bowlby ${ }^{1, *}$, J. Mark Hanson ${ }^{2}$, Jeffrey A. Hutchings ${ }^{1}$ \\ ${ }^{1}$ Department of Biology, Dalhousie University, Halifax, Nova Scotia B3H 4J1, Canada \\ ${ }^{2}$ Department of Fisheries and Oceans, PO Box 5030, Moncton, New Brunswick E1C 9B6, Canada
}

\begin{abstract}
Various biases and limitations associated with mark-recapture research have resulted in conflicting interpretations of individual movement patterns, rendering unclear the selective pressures that could be responsible for structuring populations and influencing individual behavior patterns in the marine environment. To address these issues, novel modeling techniques developed for mammalian systems were applied to trajectory data from an American lobster Homarus americanus population in order to describe quantitatively seasonal movement patterns. Basing individual- and population-level analyses on a correlated random walk model, individuals were found to belong to 1 of 2 movement types: residents or dispersers. Over the course of a year, resident animals remained in the general area of their release, whereas dispersing animals moved rapidly away from release sites in autumn and slowly returned in spring. Such movement patterns can be explained as responses to seasonal limitations in hard-substrate habitat. The effect of movement on the seasonal population distribution and structure of lobsters can have significant consequences for the sustainable exploitation of the species.
\end{abstract}

KEY WORDS: Movement heterogeneity - Ultrasonic telemetry · Correlated random walk . Distribution · Fitness $\cdot$ American lobster $\cdot$ Homarus americanus

\section{INTRODUCTION}

Movement is a fundamental part of a species' life cycle, and is both a cause and a consequence of individual life histories. In evolutionary terms, movement can arise from one or more of several factors, including (1) local extinction risk, (2) inter- or intra-species competition, (3) inbreeding avoidance, (4) temporal or spatial variability in habitat quality, and/or (5) physiological constraints (Dieckmann et al. 1999). Among individuals, movement strategies are thought to represent some form of resource partitioning that helps to modify the extent of environmental variability experienced (Levin 1992). Quantitative analysis of movement seeks to combine unpredictable individual trajectories into more regular collective patterns in order to indirectly investigate the selective pressures underlying distributions (Zollner \& Lima 1999). Such analyses are particularly useful for economically important marine species, because they allow one to evaluate potential effects of resource management policies on population dynamics (Donahue et al. 2003).

In American lobster Homarus americanus, temperature has been hypothesized to be the main factor controlling population dynamics (Aiken \& Waddy 1986), and little importance has historically been placed on other factors motivating behavior (Lawton \& Lavalli 1995). For movement behavior, kin competition and inbreeding avoidance are considered unlikely mechanisms because of population mixing during pelagic larval dispersal (Sale \& Kritzer 2003). Frequency of non-human predation on adult lobsters is thought to be extremely low (Hanson \& Lanteigne 2000, Davis et al. 2004), and physiological constraints do not appear to 
limit dispersal, given the observation that lobsters become increasingly mobile with greater body size (Wahle \& Steneck 1992). Environmental heterogeneity is likely to affect dispersal patterns, yet how this relates to habitat quality and seasonal distribution is not well understood (but see Dunnington et al. 2005).

Scale of observation is crucial when interpreting movement within ecological and evolutionary contexts (Levin 1992). For highly mobile species, the exploration of population-level consequences of movement requires individual observations over large spatial and temporal scales. In this regard, previous research on the American lobster has been limited to methodologies with good resolution at only 1 scale. Although fishery-based markrecapture studies have been used to collect data throughout large areas, these have had low temporal resolution and have been confounded by varying degrees of bias, attributable to factors such as (1) unequal catchability, (2) uncertain reporting rates, and (3) unknown levels of fishing effort among individuals (Freire \& Gonzalez-Gurriaran 1998, Dunnington et al. 2005). Intensive sampling using SCUBA has facilitated the collection of seasonal data (Karnofsky et al. 1989a) but not over large enough geographic areas to encompass movement patterns at the population level. This has contributed to conflicting conclusions between studies (Campbell 1986 cf. Comeau \& Savoie 2002).

The means by which individuals search for spatially distributed resources are critical to their success in exploiting them (Zollner \& Lima 1999). Long-distance movement can arise in populations when the fitness benefits associated with such behavior outweigh the fitness costs (Levin et al. 1984, Miller et al. 1985); this includes situations in which movement is predicted by seasonally deleterious conditions or a high risk of mortality. In addition, selection would be expected to favor the least energetically expensive mode of travel (Zollner \& Lima 1999). Over very short time-frames, an organism's movement is typically random, and the area occupied by a population increases linearly over time (Kareiva \& Shegesada 1983). Deviations emerge over longer time-frames as abiotic or biotic factors become limiting, and result in quantifiable population movement patterns. Common patterns produced by resource limitation occur when individuals are strongly divergent in the tendency to move (Austin et al. 2004), or when population movement is highly directional and corresponds to a shift in home range (Heithaus et al. 2002). Alternatively, sexual selection can act strongly on mating strategies by modifying behavior, and this can lead to divergent movement patterns between sexes (Croft et al. 2003).

To address some of the issues pertaining to scale and bias, we undertook a study of individual movement in the American lobster that combined seasonal variabil- ity in sampling effort over a large geographic area $\left(>4000 \mathrm{~km}^{2}\right.$ ) with an analytic methodology designed to account for potential sampling biases (opportunistic recaptures in space and time). Known spatial and temporal variability in habitat characteristics were compared with the rate, timing and trajectory angle of individual movements to infer motivating factors. At the population level, the roles of density-dependent interactions, physiological requirements, and phenotypic variation in structuring lobster movement were discussed within the context of dispersal theory.

\section{MATERIALS AND METHODS}

Data collection. The study was conducted in central to northern Northumberland Strait, the body of water that separates the eastern Canadian provinces of New Brunswick and Nova Scotia from the northern half of Prince Edward Island (PEI) (Fig. 1). Relative to typical American lobster habitat, the physical oceanography of the Strait is unique because it is comparatively shallow (average depth is $<20 \mathrm{~m}$ ) and bottom sediment is dominated by sand and sandy gravel (Loring \& Nota 1973). Net current flow is from north to south, with transient eddies forming along the length of the Strait (Koutitonsky \& Bugden 1991). Seasonal bottom temperatures fluctuate from $-1.6^{\circ} \mathrm{C}$ in mid-winter to more than $20^{\circ} \mathrm{C}$ in summer (Hanson \& Courtenay 1996, Petrie et al. 1996, Hanson \& Lanteigne 2000). Most of the bottom substrate is vulnerable to disturbance from ice scour during winter (Brown et al. 2001). Near the northern end of the strait, bottom topography is somewhat steeper, with depths declining to more than $40 \mathrm{~m}$ (Koutitonsky \& Bugden 1991). These deeper waters are in continuous contact with the cold intermediate layer (CIL), within which water temperatures are less than $1^{\circ} \mathrm{C}$ year-round (Gilbert \& Pettigrew 1997).

Newly molted lobsters (81 to $89 \mathrm{~mm}$ carapace length [CL]) were selected to represent first-year cohorts into the market fishery and to ensure that only mature individuals were tagged (Campbell 1986, Hudon 1987, Lawton \& Lavalli 1995). Lobsters ( $\mathrm{n}=119)$ were captured, tagged, and released between August 27 and September 7,2004, during the 8 wk summerautumn lobster fishery. The majority of study animals were obtained opportunistically during the regular commercial fishing activities of volunteer harvesters (Campbell 1986). This placed certain constraints on the tagging procedure and the group of study animals obtained: (1) the release sites were not the same as the capture locations for any tagged animal, (2) to ensure a 1:1 sex ratio among released individuals, 20 females had to be bought from seafood companies on the local wharf adjacent to the study area, and (3) study animals 

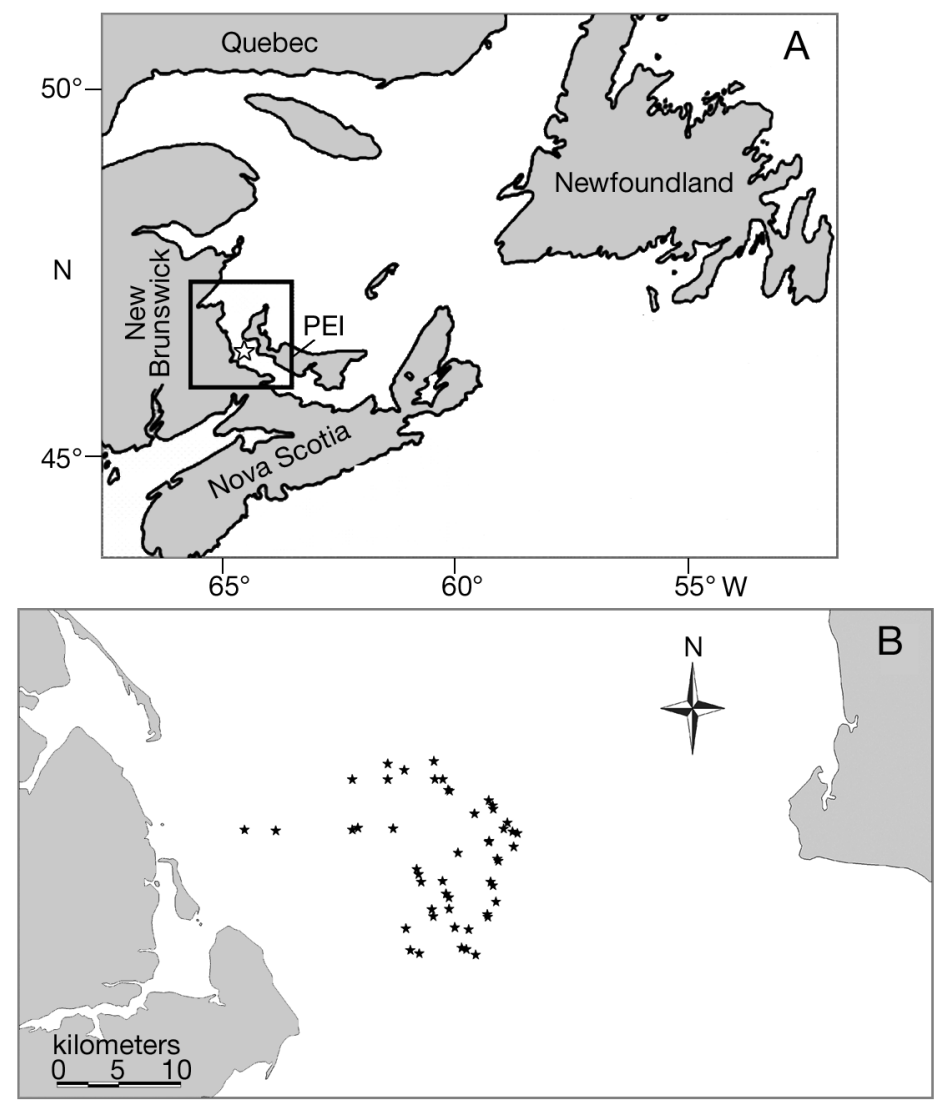

Fig. 1. (A) Gulf of St. Lawrence, showing location of Northumberland Strait within Atlantic Canada (black box) and the general location of release sites for ultrasonically tagged lobsters (ㄱ) (B) Individual release sites in central Northumberland Strait $(\star)$. Lobsters $(n=119)$ were captured, tagged and released between August 27 and September 7, 2004. PEI: Prince Edward Island

may not have been randomly selected from the general population, given that individual capture probabilities were influenced by physiological state (Jury et al. 2001). The release sites for all tagged lobsters (which were unique for each individual, Fig. 1) were concentrated in the small area of central Northumberland Strait (approximately $10 \mathrm{~km}^{2}$ ) fished by the local harvesters. There is a high probability that the study animals were captured and released within similar habitat. The group of study animals obtained was biased towards lobsters that were susceptible to traps, a bias common to most lobster tagging research (Haakonsen \& Anoruo 1994, Watson et al. 1999, Comeau \& Savoie 2002). Although trap susceptibility is known to be related to dominance behavior and within-trap lobster density (Jury et al. 2001), it is not known how either of these influence movement patterns, if at all.

The tags used were individually coded acoustic transmitters (model V13-1L-69 kHz, Vemco) with a battery life of approximately 15 mo. Each tag transmitted a unique acoustic signal at least once in a $90 \mathrm{~s}$ interval, and was externally numbered to permit identification by fishermen. Tags were attached externally to the dorsal carapace surface, offset from the median groove, using 5 min epoxy (Mastercraft, Canadian Tire Corporation). Lobsters remained out of water for approximately $30 \mathrm{~min}$ to allow the epoxy to set (Karnofsky et al. 1989a). During this time, we attempted to minimize stress on the lobsters by placing them in a shaded cooler. All lobsters (particularly the purchased females) would have been subject to physiological stresses associated with trap capture, handling and the tagging procedure; however, all lobsters were responsive and mobile when released, and appeared to be in good physical condition. Although we cannot dismiss the possibility that the tagging procedure disrupted the study animals' short-term behavioral patterns, it is unlikely to have caused substantial disturbance over the extensive duration of our study (Karnofsky et al. 1989a, Watson et al. 1999). Nonetheless, to control for possible taggingrelated biases in movement, recapture data from the first 2 days subsequent to release were excluded from our analyses.

Information on the tagging study was posted at wharves throughout New Brunswick and PEI in 2004 and 2005, with the help of the Department of Fisheries and Oceans (DFO), the Maritime Fisherman's Union (MFA) and the PEI Fisherman's Association (PEIFA). Posters requested that fishermen record the date, location and tag number of any acoustically tagged lobsters landed while fishing before re-releasing the animal, and fishermen were compensated by DFO for the selling price of a market lobster for each reported capture. Fishermen from both New Brunswick and PEI participated in data collection, recording 90 recapture events of 42 individual animals during the 2004 autumn fishing season (mid-August to mid-October) in Northumberland Strait.

Passive data collection relied on moored hydrophone receivers (model VR2, Vemco). Each unit had a 15 mo battery life and the potential to record 300000 tag detections in real time. There were 3 deployments of VR2 receivers: (1) 49 were deployed in August and were removed mid-October, 2004 (autumn deployment), (2) 25 were deployed in late October 2004 and were removed in May 2005 (winter deployment), and (3) 25 were deployed in July and removed in August 2005 (summer deployment) (Fig. 2). Units were spaced approximately $1000 \mathrm{~m}$ apart in spring and autumn, but $500 \mathrm{~m}$ apart during winter to compensate for increased 


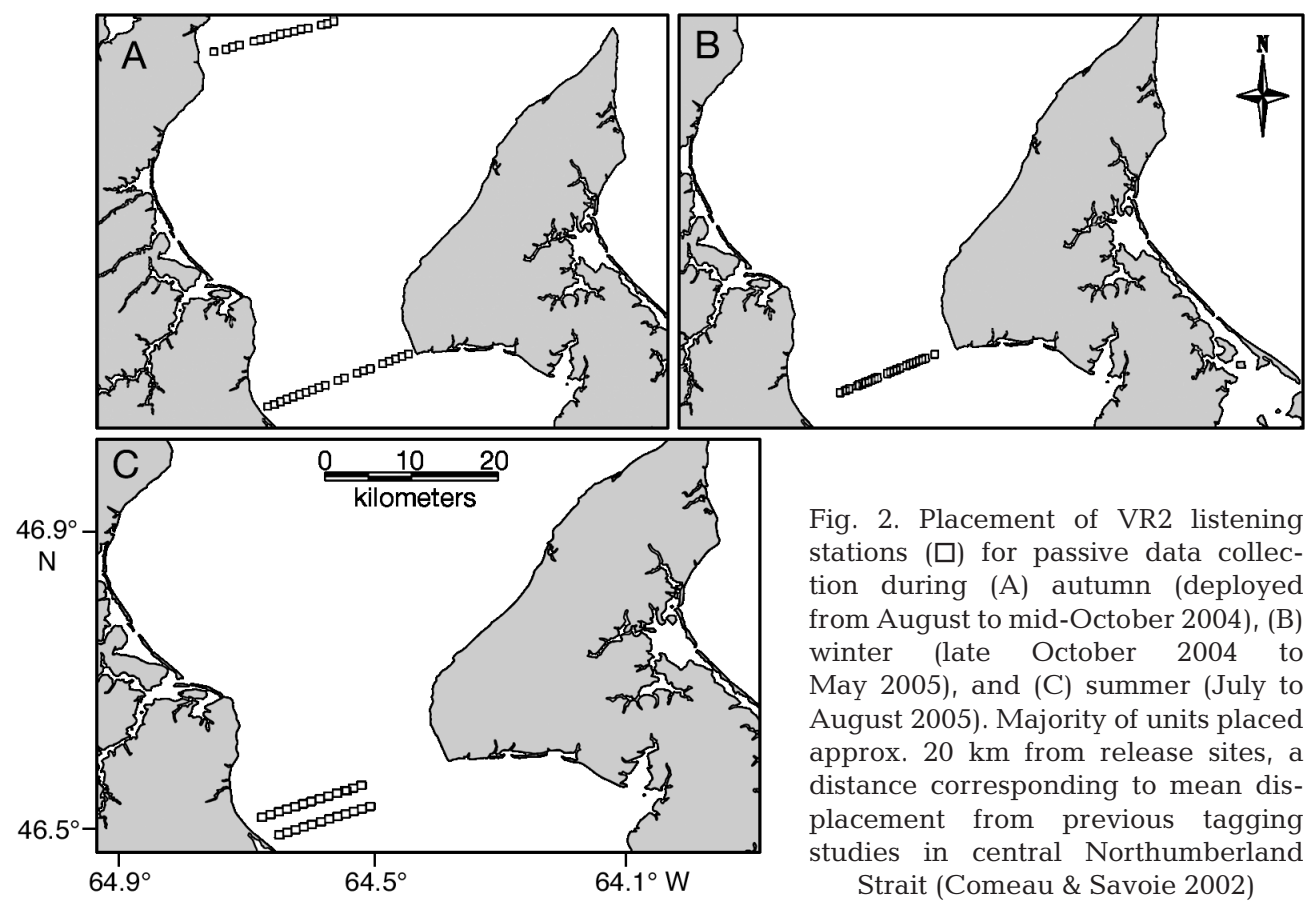

noise levels in the water column due to storm conditions and ice formation (Wolcott 1995, Comeau et al. 2002). The listening stations were successful in decoding 24571 tag transmissions by 26 individual tags. If a tag code was recorded only once by a VR2 unit instead of as a series of sequential transmissions, it was not used in the data analyses because of the possibility of erroneous identification by the receiver (Clements et al. 2005).

Active tracking was undertaken from a $7 \mathrm{~m}$ boat with a mobile receiver (model VR60, Vemco) and an omnidirectional hydrophone (model VH65, Vemco). The hydrophone was attached to a $4.5 \mathrm{~kg}$ weight and suspended below the keel depth of the boat. Although range tests indicated consistent tag identification within $300 \mathrm{~m}$ of the hydrophone over smooth bottom sediments (data not shown), acoustic tag transmissions were readily distinguishable from background static over a larger area (>500 m) (Pincock \& Voegeli 2002). Sampling sites $(\mathrm{n}=502)$ were searched following a grid pattern, with stations located $500 \mathrm{~m}$ apart over the 2004 release sites and $1000 \mathrm{~m}$ apart in other areas (Fig. 3). The maximum search rate was 10 to 12 stns per hour or approximately 60 stns per sampling day, weather permitting. Given the large size of Northumberland Strait (approximately $4600 \mathrm{~km}^{2}$ ), comprehensive sampling of the entire region was not possible; active tracking was most efficient for locating animals in the general area of the release sites. The chosen sampling sites depended primarily on daily wind and wave conditions, as well as proximity to various wharves and fuel constraints.
Statistics and modeling. The latitude and longitude (MapSource v. 6.2, Garmin International) of each release or recapture event were transformed to rectangular coordinates using MapInfo Professional (version 7.0, MapInfo Canada). The mapped straight-line displacement between points was deconstructed into step length $(\mathrm{km})$ and angle (radians) for each component of a lobster's trajectory (Batschelet 1981). Kruskal-Wallis rank sum tests were used to compare categorized data, and to determine whether the method of data collection influenced the distribution of recorded component displacements. The 3 types of data collection were not strictly equivalent: active tracking and fishery recaptures yielded time-specific point estimates, whereas VR2 stations recorded continuously through time. If continuous sampling had no effect on recorded movement, mean displacement to a VR2 station should not differ from mean displacement of the next recorded move.

Data were categorized as 1 of 3 types: (1) the first decoding of a tag by a VR2 station, (2) the next recapture of that tag (either by the same VR2 receiver, a different VR2 station, or a fisherman), and (3) all other recaptures. Type 2 data had marginally lower mean displacement when compared with Type 1 data (Kruskal-Wallis, $\mathrm{p}=0.04$ ). However, no differences among data types were detected when VR2 data were converted to point estimates (conditioned on the initial detection of an individual by a VR2, disregarding the remainder of the continuous series of identifications) (Kruskal-Wallis, $\mathrm{p}=0.53$ ). This anomaly suggests that 
study animals tended to stop along the VR2 line. All further analyses were based on displacement data from point estimates only.

Most techniques used to analyze movement are based on diffusion models, which describe a population's spread and rate of spread through space using trajectories of individuals (Turchin 1998). One basic model is a correlated random walk (CRW), which calculates the rate of change of area used by an animal or a population over time, incorporating observed step lengths (straight line distance between recapture locations) and turning angles (the difference between successive angular vectors) into a linear projection of expected net squared displacement $\left(R_{\mathrm{n}}{ }^{2}\right)$ from the release location (Kareiva \& Shegesada 1983, Turchin 1998). This null model incorporates the assumptions that animals move without limiting factors and that they are equally likely to turn left or right, albeit with a tendency to persist in their original direction.

The CRW model also incorporates the assumption that successive observations of individuals are independent (Turchin 1998). Independence was highly likely in the present study because of the long and varied intervals between recapture events (Swihart \& Slade 1985). However, a subset of individual trajectories was tested for autocorrelation among measurements using Schoener's ratio test. Schoener (1981) defined independence as resulting when an animal's

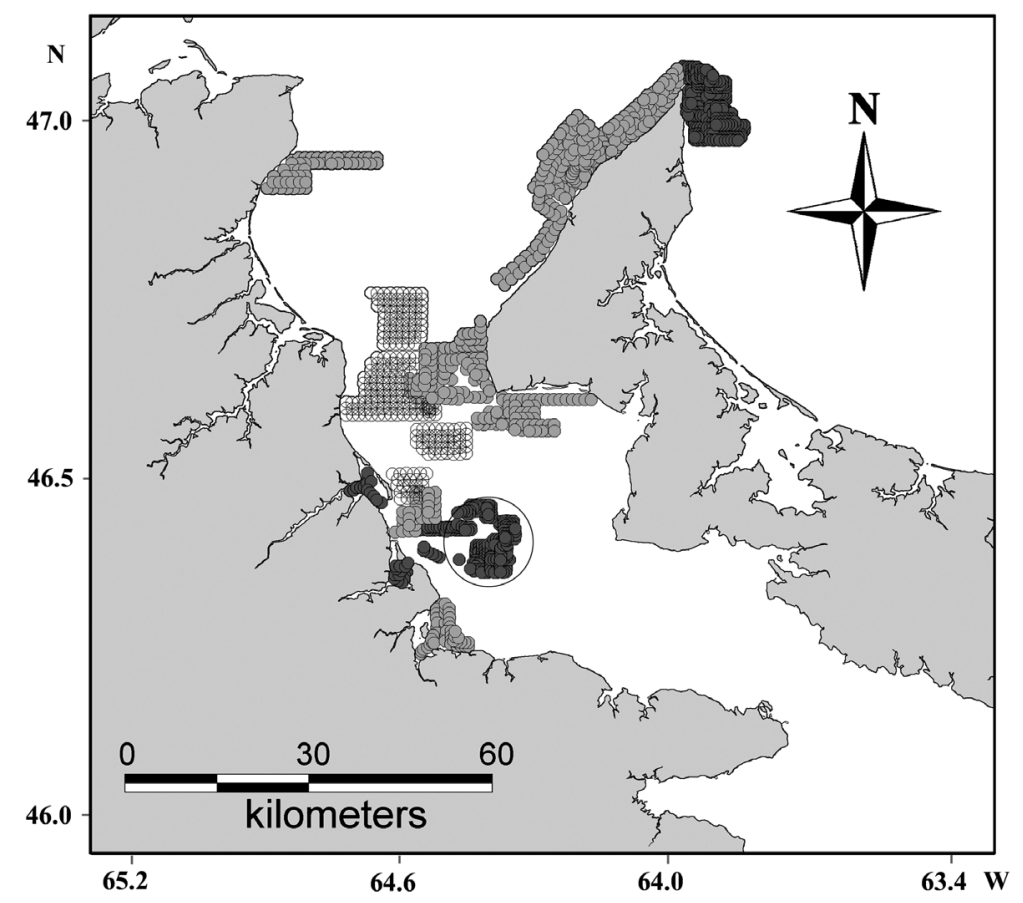

Fig. 3. Active tracking sites searched with the VR60 mobile receiver in May (๑), June (๑) and July/August (O) 2005. The 2004 release sites (enclosed in black circle) were searched at the beginning and end of the sampling period, whereas all other sites were visited once position at $t+1$ is not a function of its position at time $t$. Empirically, this occurs when the ratio of mean squared distance between successive observations to mean squared distance from the bivariate center of activity falls above a critical value (Swihart \& Slade 1985). For all individual trajectories tested, the null hypothesis $\left(H_{0}\right)$ of independence was retained (data not shown).

One consequence of combining telemetry-based data with fishery-based data is that individual identifications are opportunistic or non-random and nonuniform over space and time. Data are collected without having to standardize across methods for differences in detection efficiency or detection range (Pittman \& McAlpine 2003). Thus, empirical methods of analyzing movement are not appropriate (Turchin 1998), and techniques that account for repeated sampling of individuals are required (Millar \& Anderson 2004). Although such statistical models have recently been developed to describe mammalian behavior, they have not been widely applied in fisheries science. Full theoretical justification for the applicability of the following methods can be found in Whitehead (2001) for Maximum Likelihood models and in Morales et al. (2004) for Bayesian analyses of switching models. In brief, the movement analysis portion of SOCPROG software (compiled version for MATLAB 7.0, H. Whitehead [2005] Public communication. Programs for analyzing social structure. Available at: http://myweb. dal.ca/ hwhitehe/MANUAL.htm\#TOC2_1) simulates the expected number of individuals within an area over time based on actual recapture histories, using individual recapture locations as a proxy for sampling effort (Whitehead 2001, H. Whitehead [2005]. Public communication. Programs for analyzing social structure. Available at: http://myweb. dal.ca/ hwhitehe/MANUAL.htm\#TOC2_1). Using a discrete movement model, maximum likelihood estimation through a bootstrap of 10000 repetitions (assuming a Poisson distribution) determines the movement parameters that minimize the difference between observed and expected recaptures (Hilborn 1990, Whitehead 2001). The model output describes the lagged identification rate (LIR), defined by Whitehead (2001) as the probability that an individual found in the study area at time $t_{0}$ is also in the study area at time $t$ (which is the probability that an individual is in the study area after time $t$ divided by the no. of individuals in the study area). LIR plotted against lag time describes individual dispersal from release sites (study area). A declining function shows how rapidly individuals are leaving (dispersing), while a 
leveling-off over large time lags indicates that animals are either (1) returning to the study area (exhibiting a cyclical movement pattern), or (2) that some are permanent residents of the study area (indicating heterogeneity in movement types) (Whitehead 2001). These 2 options were evaluated independently to determine whether one or both patterns were evident in the data.

Evidence of cyclical movements (emigration from and re-immigration to the study area) was evaluated using SOCPROG's movement in continuous space component, which relies on the uncorrelated random walk model to estimate diffusion rate (Whitehead 2001). A probability density function for lobster movement over time was created from summed log-likelihoods of individual net squared displacement $\left(R_{\mathrm{n}}{ }^{2}\right)$ in specified time lags, with precision estimates produced by jackknife re-sampling (Efron \& Gong 1983). The $H_{0}$ predicts that $R_{\mathrm{n}}{ }^{2}$ plotted against time lag will increase linearly from 0 (Turchin 1998, Whitehead 2001). If $R_{\mathrm{n}}{ }^{2}$ decreases at large time lags, it is indicative of cyclical movement of individuals in the study population (Whitehead 2001).

Measures of $R_{\mathrm{n}}{ }^{2}$ are based on, but do not specifically confirm to, actual geographic orientation; therefore, Moore's Modified Rayleigh Test (MRT) was used to determine the predominant direction of movement of lobsters during summer and autumn 2004. Angular vectors from component displacements were weighted as a function of their rank distance and compared with the $H_{0}$ of a uniform circular distribution using critical values reported by Moore (1980). Significance suggested that animals are moving in a preferred direction, provided the observed distribution of angles is unimodal (Batschelet 1981, Diamond \& Hankin 1985).

Observed movement data were tested for leptokurtosis using Shapiro-Wilks' $W$-test (Royston 1982). One reason that movement data can be leptokurtic is that the diffusion distribution comes from groups of individuals exhibiting divergent behavior (Skalski \& Gilliam 2000). Such movement types, often termed residents and dispersers (as defined by Bergman et al. 2000), can be delineated quantitatively depending on the degree of divergence between them using a simplified Bayesian switching model (Morales et al. 2004) run in winBUGS (see www.mrc-bsu.cam. ac.uk/bugs/winbugs/contents. shtml for further information). If divergent movement types are present in the study population, one would expect the observed distribution of displacement distances (step length) to be bimodal. Residents should exhibit significantly smaller median step lengths than dispersers, and the values would be more concentrated around the central tendency. For the observed distribution of angles, residents would be expected to turn randomly whereas dispersers would exhibit directional movement
(Morales et al. 2004). The switching model describes the likelihood of such movement heterogeneity based on the difference between the shape and scale parameters (for step length) and mean direction and mean cosine (for angles) of resident and disperser movement distributions (classified simultaneously by the model).

By conditioning the CRW model on mean daily displacement of an individual, likelihood functions for movement parameters (given observed positions) were simulated by independent draws from Weibull (for step length) and Wrapped Cauchy (for angular) distributions, considering 1 or 2 independent movement states. Posterior estimates of movement parameters $(a, b, m u$ and $r h o$ ) were generated by Gibbs sampling for 2 models (Morales et. al. 2004), using uninformative priors for Weibull shape and scale parameters ( $a$ and $b$ ) and Wrapped Cauchy mean direction and mean cosine ( $m u$ and $r h o$ ). The first model incorporated the assumption that all individuals belonged to a single movement type, and the second placed each observation into 1 of 2 movement types and then estimated model parameter values for each type. Credible limits around parameter values corresponded to the quantiles of their posterior distributions. Unfortunately, the Deviance Information Criterion is not a reliable estimator for switching models (Speigelhalter et al. 2002), so model choice was based on the fit of observed data to simulated distributions and the degree of divergence between parameter estimates for the 2-state model. Strictly speaking, a hierarchical 2-state model comparing variability within and among individuals would have been better than the present analysis on mean observed step length and trajectory angles. However, there were not enough data on specific individuals to justify the added complexity of this type of hierarchical analysis.

\section{RESULTS}

Of the 119 animals tagged in central Northumberland Strait, 3 were removed by harvesters during the autumn fishing season without recapture information being collected (even though the tags were returned) and an additional 54 were located by active tracking, VR2 listening stations and/or fishermen recaptures. Our recapture rate of $48 \%$ is similar to that reported for other lobster tagging projects in Atlantic Canada (Wilder 1963, Comeau \& Savoie 2002). All recaptures were opportunistic, so recapture histories differed markedly among animals. New individuals were identified continually throughout the study and mean number of recaptures for a specific animal was 4 (range 1 to 19). Almost all animals caught by fishermen were also detected by VR2 stations (48 individuals, 142 recap- 
tures), while relatively stationary animals were found only by active tracking (23 individuals, 26 recaptures).

Considering just the VR2 stations, 34 of the 49 receivers were recovered from the autumn deployment, 21 of the 25 from the winter deployment, and all 25 were recovered from the summer deployment. Displacement by storms and scallop dragging were likely principle causes of receiver loss. For the autumn deployment, none of the receivers placed in the northern line detected lobster (Fig. 2); however, it is possible that some individuals reached this area after sensors were removed (between October 18 and 27, 2004). Overall, receivers detected 24 individuals in autumn (all on multiple receivers) 1 individual (on 4 different receivers) in winter, and 6 (all on multiple receivers) in spring. There was no evidence that any of the receivers malfunctioned during the study.

Individual component movement rates differed among seasons, being similarly high during autumn and spring, and decreasing by an order of magnitude over winter (Kruskal-Wallis; p $<<0.001$ ) (Fig. 4). Overall, individual trajectories summed to an average of $24.3 \mathrm{~km}(\mathrm{SD} \pm 17.7 \mathrm{~km})$ during the entire study (minimum: $<1 \mathrm{~km}$, maximum: $86 \mathrm{~km}$ ). Considering only the first recapture of an individual by fishermen (an estimator which is comparable to single mark-recapture research), mean distance traveled was $10.8 \mathrm{~km}$ (SD \pm $10.7 \mathrm{~km}$ ). There were insufficient data to stratify trajectory analyses by sex, but Kruskal-Wallis rank sum tests on movement characteristics (displacement, turning

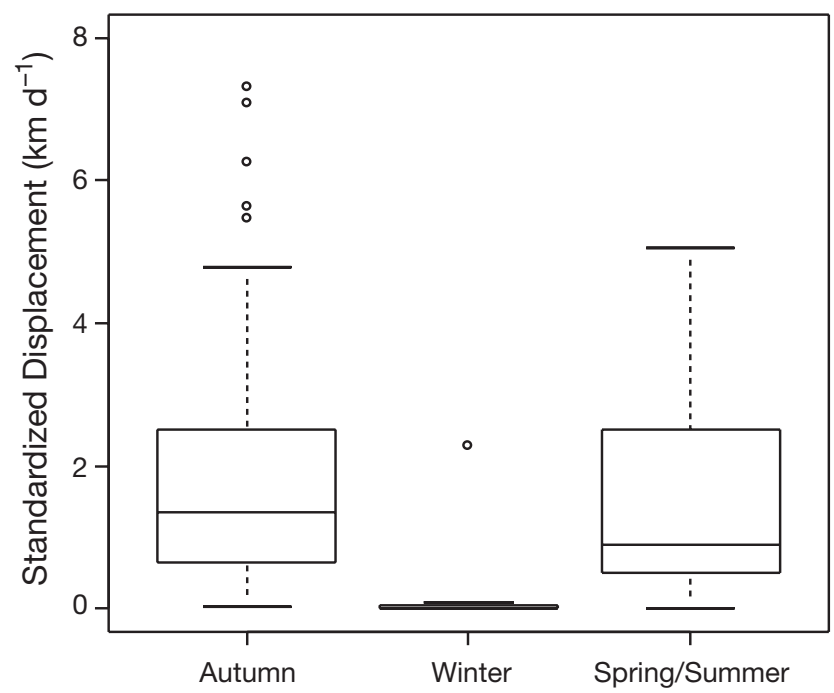

Fig. 4. Homarus americanus. Boxplot comparing standardized component displacement among seasons (autumn, winter, and spring/summer), pooling data across individuals. Median displacement was $1.3 \mathrm{~km} \mathrm{~d}^{-1}$ (quantiles: 0.7 and $2.5 \mathrm{~km} \mathrm{~d}^{-1}$ ) and $0.9 \mathrm{~km} \mathrm{~d}^{-1}$ (quantiles: 0.5 and $2.5 \mathrm{~km} \mathrm{~d}^{-1}$ ) in autumn and spring/summer, respectively, which differed significantly from $0.01 \mathrm{~km} \mathrm{~d}^{-1}$ (quantiles: 0.008 and $0.04 \mathrm{~km} \mathrm{~d}^{-1}$ ) in winter. o: outlier angle, movement rate) between sexes indicated no significant difference (data not shown).

Dispersal was primarily northward during autumn 2004 along the long axis of Northumberland Strait at a mean angle of $328^{\circ}$ relative to due North (MRT, p << 0.001) (Fig. 5). LIR of individuals declined rapidly during autumn, indicating that animals dispersed rapidly following release (Fig. 6). However, LIR leveled off on an annual scale, suggesting that 2 movement patterns were possible in the study population: (1) relatively fast emigration from the study area of most individuals during early autumn with some overwintering in situ, and/or (2) relatively fast emigration coupled with some re-immigration to the study area during spring and summer (Whitehead 2001, H. Whitehead [2005] Public communication. Programs for analyzing social structure. Available at: http://myweb. dal.ca/ hwhitehe/ MANUAL.htm\#TOC2_1).

Mean diffusion rates $\left(\mathrm{km}^{2} \mathrm{~d}^{-1}\right)$ differed significantly throughout the year, being low immediately after animals were tagged, remaining high throughout the next 2 months, and reaching a minimum in spring/ summer (Fig. 7a). This corresponded to a linear increase in net squared displacement during autumn, with a slight reduction in $R_{\mathrm{n}}{ }^{2}$ during spring/summer (Fig. 7b). Taking these results together, some lobsters were quickly dispersing from central Northumberland Strait in autumn, and meandering back in spring and summer. Actual distances from root-mean-squareddisplacement revealed that animals traveled approxi-

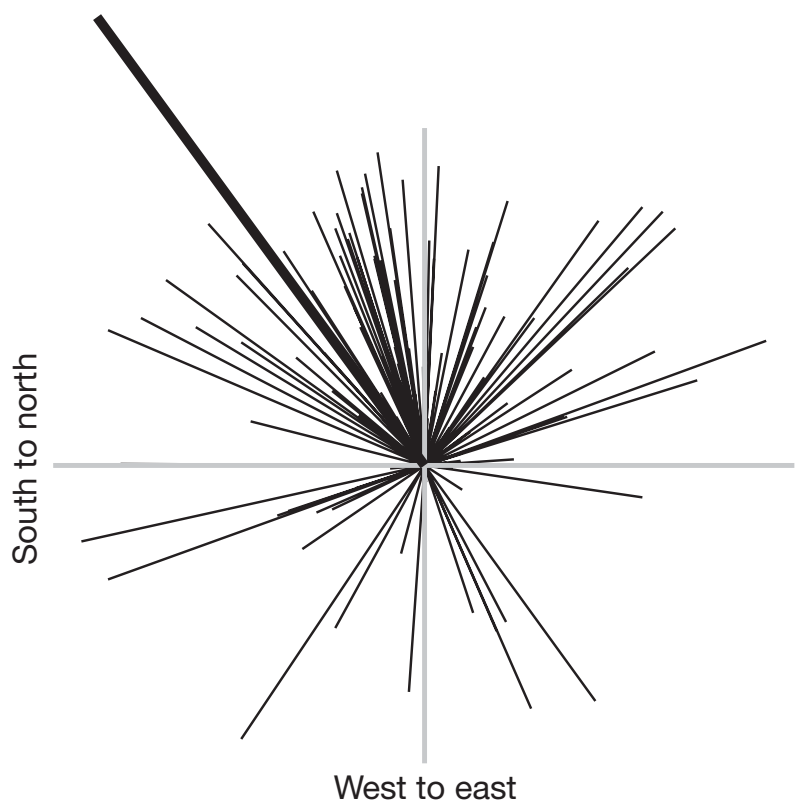

Fig. 5. Homarus americanus. Distribution of angular vectors from all recorded component moves in autumn 2004, pooling data across individuals. Mean compass direction (thick black line) is $328^{\circ}$ (where $0^{\circ}=$ North), which corresponds roughly to the longitudinal axis of Northumberland Strait 


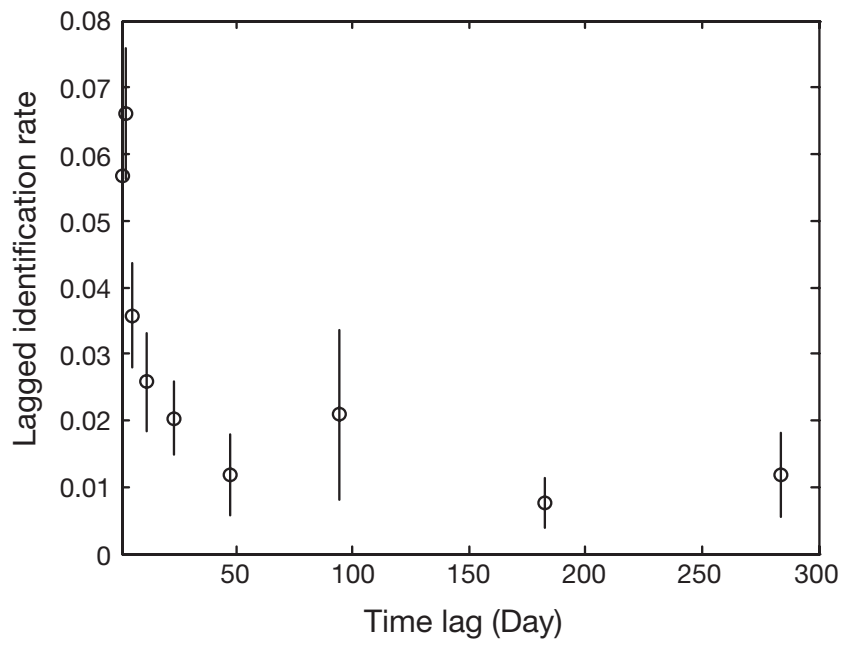

Fig. 6. Homarus americanus. Lagged identification rate (LIR) against time lag, where Day 0 corresponds to August 28, 2004. Steep decline over small time lags (September to October) describes how quickly individuals are leaving the study area after release. Leveling-off over long time lags (November to August) suggests lobsters are either returning to the study area or that they never left it

mately $44 \mathrm{~km}$ out of central Northumberland Strait in autumn and returned approximately half that distance the following spring; however, distance returned was highly variable among individuals.

The step length distribution, constructed by fitting a single CRW model (assuming 1 type of movement behavior in the study population), estimated median step length at $0.97 \mathrm{~km} \mathrm{~d}^{-1}$ and median trajectory angle at $349^{\circ}$ (1.76 radians) relative to due North. In comparison, the double CRW model indicated significantly different median step lengths for resident and dispersing animals of $0.3 \mathrm{~km} \mathrm{~d}^{-1}$ and $2.5 \mathrm{~km} \mathrm{~d}^{-1}$, respectively, and placed $72 \%$ of lobsters in the dispersing category (Fig. 8). Dispersing lobster tended to move in the same direction, as indicated by the high mean cosine (rho2) of the angular distribution, as well as the narrow quantile interval of median angle (mu2). Conversely, variance around the median trajectory angle was extremely high for residents, as would be expected of animals that remained close to release sites. Based on the divergence between parameter estimates for the 2state model, it is likely that the study population was composed of 2 distinct behavioral types, a conclusion supported by leptokurtic distributions of displacement parameters (Shapiro-Wilks' $W$-test, $\mathrm{p}=0.001$ ).

\section{DISCUSSION}

Distinct resident and disperser movement behaviors, whereby dispersers emigrate and re-immigrate to the study area, have not been previously reported for coastal American lobster populations. Although heterogeneity in movement behavior among individuals has been documented (Karnofsky et al. 1989b, Watson et al. 1999), the timing, extent and cyclical movement pattern of dispersers relative to residents has not been previously quantified.

Within Northumberland Strait, previous fisherydependent mark-recapture studies have been unable to identify well-defined movement patterns, and none were of sufficiently high temporal resolution to detect seasonal changes in movement (Comeau \& Savoie 2002). Although extensive cyclical movement of Homarus americanus in response to storm conditions is common along the Atlantic coast, it involves limited (<5 km) horizontal displacement (Haakonsen \& Anoruo 1994, Lawton \& Lavalli 1995). Intensive sampling in localized areas has documented evidence suggestive of resident and disperser movement behavior (Ennis 1984, Karnofsky et al. 1989b), but individuals could not be followed over large spatial scales. However, other movement characteristics are quite consistent with data from previous research in Northumberland Strait, and it is likely that similar movement patterns would have been observed with greater data resolution. Mean distance traveled to first recapture in our study was slightly higher than previous estimates ( 7.3 to $8.8 \mathrm{~km}$ in the literature compared with $10.8 \mathrm{~km}$ reported here), especially considering that the time between release and recapture was much shorter (cf.
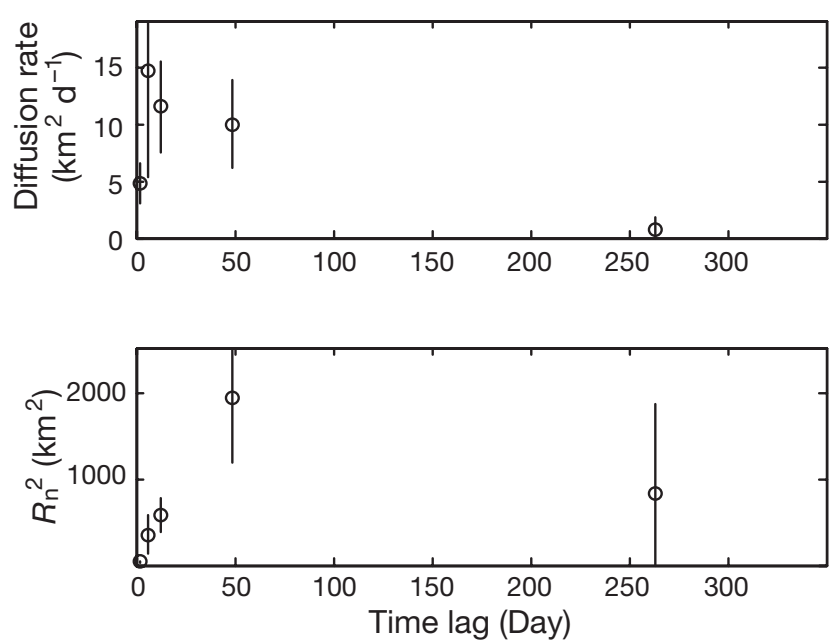

Fig. 7. Homarus americanus. (A) Diffusion rate and (B) net squared displacement $\left(R_{\mathrm{n}}{ }^{2}\right)$ (plus jackknifed errors) of individually identifiable lobsters over time from release, where Day 0 corresponds to August 28, 2004. Net squared displacement increased linearly throughout September and October 2004 (B) and was associated with fast diffusion rates (A). However, $R_{\mathrm{n}}{ }^{2}$ and diffusion rate declined in spring 2005 (May to August), which indicates movement towards release sites or re-immigration to the study area 


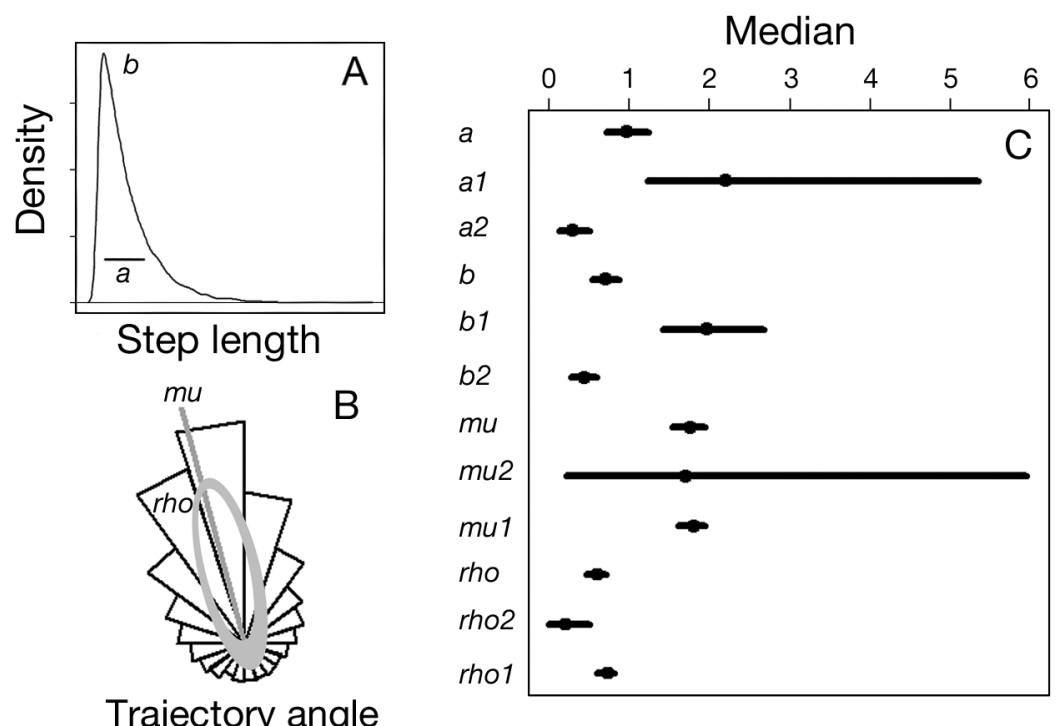

Fig. 8. Homarus americanus. (A) Visual representation of the characteristics of the Weibull distribution described by its shape (a) and scale (b) parameters. (B) Visual representation of the Wrapped Cauchy distribution showing mean angle $(m u)$ and concentration parameter, mean cosine $(r h o)$. (C) Comparison of parameter estimates (and quantiles) between the single $(a, b, m u$ and $r h o)$ and double Bayesian switching model where $a 1, b 1$, mu1 and rho1 represent dispersers and $a 2, b 2, m u 2$ and $r h o 2$ represent residents. In all cases the single model estimate is intermediate, and quantiles of the double model estimates (excluding mu1 and mu2) do not overlap

Comeau \& Savoie 2002). However, this may have resulted from differences in the size of individuals, given that lobster tagged by Comeau \& Savoie (2002) ranged from 63.5 to $80.0 \mathrm{~mm}$ CL compared with 81 to $89 \mathrm{~mm}$ CL in the present study.

There was a pronounced positive correlation between individual movement rates and bottom temperature. Movement rates decreased by a factor of 10 during the cold months (December to April) compared with either the autumn or spring/summer periods. Bottom water temperatures in Northumberland Strait followed a similar pattern, with maximum temperatures during August to October that steadily decreasing to a minimum in January and February, and not substantially increasing again until May (Petrie et al. 1996). This supports previous research that found that lobster activity was highly correlated with temperature (Aiken \& Waddy 1986, Drinkwater et al. 1996), decreasing substantially during winter (Karnofsky et al. 1989a). Cool bottom water in spring 2005 may also have contributed to the slower diffusion rates of lobsters returning as opposed to leaving central Northumberland Strait. Being ectothermic, lobsters would not be physiologically able to move as quickly in cooler water (Lawton \& Lavalli 1995). However, temperature fluctuation does not adequately explain the divergent movement types in the population.
Resident and disperser movement strategies may reflect trade-offs to individual fitness (Dieckmann et al. 1999). In Northumberland Strait, resident behavior may be selectively advantageous for growth and recruitment2 factors known to be major determinants of movement in many taxa, and almost certainly directly linked to fitness (Skalski \& Gilliam 2000). During summer and autumn, the central Strait probably represents ideal lobster habitat given that bottom water temperatures are warm, food is abundant, and adult lobster are densely distributed (Drinkwater et al. 1996, Comeau \& Savoie 2002). In spring, water temperature increases faster than in deeper water to the north (Petrie et al. 1996), so resident animals could become active sooner and would have a greater opportunity to procure resources. Also, resident animals would not be subject to any physiological cost associated with dispersal (Dieckmann et al. 1999). Surprisingly, resident behavior was not the dominant movement strategy, so any fitness advantage in terms of growth or reproduction is presumably outweighed by a substantial cost for the bulk of the population.

Rapid, long-distance movement by dispersers was undertaken at the end of the breeding and molting season (Comeau \& Savoie 2001), which suggests that dispersal behavior may be density-dependent. Variable severity of ice scour and wave action to shallow bottom sediments (Brown et al. 2001), coupled with the minimal activity levels of lobster in near-zero temperatures (Karnofsky et al. 1989a), would require animals to secure shelter beneath hard substrate features or in deep water to minimize over-wintering mortality (Ennis 1984). In Northumberland Strait, hard sediment and deep water is sparse near the center, but becomes progressively more abundant to the north (Loring \& Nota 1973). Searching for over-wintering habitat could theoretically lead to long-distance movement, because animals might have to travel upwards of $30 \mathrm{~km}$ before locating adequate shelter. A CRW characterizes movement in environments with frequent localized disturbance, because it minimizes the amount of revisited area while concurrently maintaining high inter-annual geographical variation in spatial location (Kareiva \& Shigesada 1983, Bergman et al. 2000). Given that the environmental conditions contributing to mortality in adult lobster would be unpredictable, they would presumably select for similarly spatially and temporally variable dispersal. 
A temporal switch in habitat suitability from summer to winter for adult lobster could arise if high-quality shelter only became limiting during winter (Bergman et al. 2000), when it would not be possible for individuals to remain in soft-sediment burrows (Comeau \& Savoie 2002). Once the probability of environmentally induced mortality became negligible, individuals could return to the central Strait to exploit favorable summer conditions. Such separation of seasonal habitats and cyclical movement is not uncommon in coastal or estuarine areas where abiotic conditions change dramatically (Diamond \& Hankin 1985, Watson et al. 1999). Yet, it is unlikely that dispersal is as energetically efficient as resident behavior, or would be the preferred movement strategy. Intra-specific competitive interactions to secure shelter, whereby evicted animals leave the immediate area, are well described for adult lobsters (Karnofsky \& Price 1989). Such site fidelity was serendipitously corroborated in the present study by the tendency of lobsters to stop along the VR2 line, where the cinderblock moorings provided high-quality lobster shelter (Jensen et al. 1994, Castro et al. 2001). The positive correlation between mobility and trap catchability observed in this study is consistent with the hypothesis that energetic expenditures by dispersing lobsters are higher than for residents. It also suggests that the study animals initially tagged were biased towards dispersers.

Seasonal habitat-limitation would affect both sexes equally (Doherty \& Fowler 1994, Hutchings \& Gerber 2002) and, as expected, sex was not a significant predictor of movement in this study. This result is contrary to previous work, which reported male-biased (Jury et al. 1994) and female-biased (Campbell \& Stasko 1986) movement in coastal Homarus americanus populations. Such bias has most frequently been attributed to selective pressures acting on reproduction strategies (Haakonsen \& Anoruo 1994) or different physiological requirements between the sexes (Jury et al. 1994). However, discrepancies may be a question of the scale of data collection, data biases in fisherydependent research, or sex-biased movement during a portion of the year. Movement patterns that change during the breeding season are common in a range of taxa (see examples in Bergman et al. 2000). If such a pattern exists for lobsters, it could underlie the inconsistencies in results among studies, especially when animals are released outside, but recaptured during, the breeding season. The potential for bias was much less in the present study because data collection was minimal during the main breeding season, and sampling effort was accounted for in the analyses.

One difficulty in using opportunistic identifications of individuals is that the true scale of annual lobster movements is not known due to the variation in time between successive recaptures. This problem was especially pronounced in the present study, because recapture effort was extremely limited from November 2004 to early May 2005. Nonetheless, dispersal rates of lobsters remained high throughout autumn data collection. To obtain an accurate picture of actual geographic distances covered by dispersers, it would be necessary to record trajectories until dispersal rates fell to near-zero. Fortunately, underestimating root-meansquared displacement does not affect conclusions regarding the behavioral decisions of individuals. It is likely that the movement patterns described here would be more pronounced in a study with greater temporal resolution.

Seasonal distribution patterns do not suggest that lobsters in central Northumberland Strait form a discrete population. Rather, the movement patterns described here are consistent with the hypothesis that intra-specific competitive interactions maintain behavioral heterogeneity in movement irrespective of genetic polymorphisms or population separation (Levin et al. 1984, Skalski \& Gilliam 2000). Therefore, it is unclear where the study animals would have originated. Miramichi Bay to the north of Northumberland Strait supports a higher density of both juvenile and adult lobsters throughout the year (Comeau et al. 2004). It is possible that Northumberland Strait is a fringe habitat relative to the more productive area to the north (Hanski 1998), and the density and distribution of adult lobsters throughout the year could be largely dependent on immigration from Miramichi Bay. Future research on the degree of mixing between central Northumberland Strait and surrounding lobster settlement areas would be beneficial to better understand habitat-mediated distribution patterns.

In commercial fisheries, species' population structure, seasonal distribution, genetic composition, and recruitment limitations are vital information for the development of sustainable management policies (Pittman \& McAlpine 2003). The present study demonstrates how dispersal data can be modeled in such a way that reduces some of the ambiguity surrounding these fundamental questions in situations where manipulative experiments are infeasible. The ecological benefits of alternative conservation strategies, such as habitat-enhancement programs, protected areas, or stock enhancement, can then be modeled for a given species. Of additional benefit from a management perspective is the fact that the collection of dispersal data requires resource users to be an integral part of the research program. This interaction enhances the exchange of information between science and industry, and can potentially increase community support for conservation initiatives. 
Acknowledgements. Special thanks to the Lobster Group at the Department of Fisheries and Oceans in Moncton, New Brunswick, and to the dedicated members of MFU and PEIFA for field assistance. Thanks to I. Johnson, N. den Heyer, and $\mathrm{H}$. Whitehead for discussions on statistical methods, and to L. Weir, M. Comeau, D. Fraser and 3 anonymous reviewers for helpful comments on the manuscript. This research was conducted in collaboration with the MFU, PEIFA, DFO, and Dalhousie University. Support for this study was obtained from a Fisheries Science Collaborative Program Fund (Fisheries and Oceans Canada) grant to J.M.H., and an NSERC Canadian Graduate Scholarship to H.D.B.

\section{LITERATURE CITED}

Aiken DE, Waddy SL (1986) Environmental influence on recruitment of the American lobster, Homarus americanus: a perspective. Can J Fish Aquat Sci 43:2258-2270

Austin D, Bowen WD, McMillan JI (2004) Intraspecific variation in movement patterns: modeling individual behaviour in a large marine predator. Oikos 105:15-30

Batschelet E (1981) Circular statistics in biology, Academic Press, New York

Bergman CM, Schaefer JA, Luttich SN (2000) Caribou movement as a correlated random walk. Oecologia 123: 364-374

Brown TG, Jordaan IJ, Croasdale KR (2001) A probabilistic approach to analysis of ice loads for the Confederation Bridge. Can J Civ Eng 28:562-573

Campbell A (1986) Migratory movements of ovigerous lobsters, Homarus americanus, tagged off Grand Manan, Eastern Canada. Can J Fish Aquat Sci 43:2197-2205

Campbell A, Stasko AB (1986) Movements of tagged American lobsters, Homarus americanus, off southwestern Nova Scotia. Can J Fish Aquat Sci 42:229-238

Castro KM, Cobb JS, Wahle RA, Catena J (2001) Habitat addition and stock enhancement for American lobsters, Homarus americanus. Mar Freshw Res 52:1253-1261

Clements S, Jepsen D, Karnowski M (2005) Optimization of an acoustic telemetry array for detecting transmitterimplanted fish. N Am J Fish Manag 25:429-436

Comeau M, Savoie F (2001) Growth increment and molt frequency of the American lobster (Homarus americanus) in the Southwestern Gulf of St. Lawrence. J Crustac Biol 21: 923-936

Comeau M, Savoie F (2002) Movement of American lobster (Homarus americanus) in the southwestern Gulf of St. Lawrence. Fish Bull 100:181-192

Comeau LA, Campana SE, Castonguay M (2002) Automated monitoring of a large-scale cod (Gadus morhua) migration in the open sea. Can J Fish Aquat Sci 59:1845-1850

Comeau C, Hanson JM, Mallet M, Savoie F (2004) Stock status of the American lobster, Homarus americanus, in the Lobster Fishing Area 25. Can Atl Fish Sci Advis Comm Res Doc 04/054

Croft DP, Albanese B, Arrowsmith B, Botham MW, Krause J (2003) Sex-biased movement in the guppy (Poecilia reticulata). Oecologia 137:62-68

Davis A, Hanson JM, Watts H, MacPherson H (2004) Local ecological knowledge and marine fisheries research: the case of white hake (Urophycis tenuis) predation on juvenile American lobster (Homarus americanus). Can J Fish Aquat Sci 61:1-11

Diamond N, Hankin DG (1985) Movements of adult female Dungeness crabs (Cancer magister) in northern California based on tag recoveries. Can J Fish Aquat Sci 42:919-926
Dieckmann U, O'Hara B, Weisser W (1999) The evolutionary ecology of dispersal. Trends Ecol Evol 14:88-90

Doherty P, Fowler T (1994) An empirical test of recruitment limitation in a coral reef fish. Science 263:935-939

Donahue M J, Holyoak M, Feng C (2003) Patterns of dispersal and dynamics among habitat patches varying in quality. Am Nat 162:302-317

Drinkwater KF, Harding GC, Mann KH, Tanner N (1996) Temperature as a possible factor in the increased abundance of American lobster, Homarus americanus, during the 1980s and early 1990s. Fish Oceanogr 5:176-193

Dunnington MJ, Wahle RA, Bell MC, Gerladi NR (2005) Evaluating local population dynamics of the American lobster, Homarus americanus, with trap-based mark-recapture methods and seabed mapping. NZ J Mar Fresh Res 39: 1253-1276

Efron B, Gong G (1983) A leisurely look at the bootstrap, the jackknife, and cross-validation. Am Stat 37:36-48

Ennis GP (1984) Small-scale seasonal movements of the American lobster, Homarus americanus. Trans Am Fish Soc 113:336-338

Freire J, Gonzalez-Gurriaran E (1998) New approaches to the behavioural ecology of decapod crustaceans using telemetry and electronic tags. Hydrobiologia 371/372: 123-132

Gilbert D, Pettigrew B (1997) Inter-annual variability (1948-1994) of the CIL core temperature in the Gulf of St. Lawrence. Can J Fish Aquat Sci 54 (Suppl 1):57-67

Haakonsen HO, Anoruo AO (1994) Tagging and migration of the American lobster, Homarus americanus. Rev Fish Sci 2:79-93

Hanski I (1998) Metapopulation dynamics. Nature 396:41-49

Hanson JM, Courtenay SC (1996) Seasonal use of estuaries by winter flounder in the southern Gulf of St. Lawrence. Trans Am Fish Soc 125:705-718

Hanson JM, Lanteigne M (2000) Evaluation of Atlantic cod predation on American lobster in the southern Gulf of St. Lawrence, with comments on other potential fish predators. Trans Am Fish Soc 129:13-29

Heithaus MR, Dill LM, Marshall GJ, Buhleier B (2002) Habitat use and foraging behavior of tiger sharks (Galeocerdo cuvier) in a seagrass ecosystem. Mar Biol 40: $237-248$

Hillborn R (1990) Determination of fish movement patterns from tag recoveries using maximum likelihood estimators. Can J Fish Aquat Sci 47:635-643

Hudon C (1987) Ecology and growth of postlarval and juvenile lobster, Homarus americanus, off Ìles de la Madeleine (Quebec). Can J Fish Aquat Sci 44:1855-1869

Hutchings JA, Gerber L (2002) Sex-biased dispersal in a salmonid fish. Proc R Soc Lond B 269:2487-2493

Jensen AC, Collins KJ, Free EK, Bannister RCA (1994) Lobster (Homarus gammarus) movement on an artificial reef: the potential use of artificial reefs for stock enhancement. J Crustac Res 67:198-211

Jury SH, Kinnison MT, Howell WH, Watson WH (1994) The behaviour of lobsters in response to reduced salinity. J Exp Mar Biol Ecol 180:23-37

Jury SH, Howell H, O'Grady DFO, Watson WH (2001) Lobster trap video: in situ video surveillance of the behaviour of Homarus americanus in and around traps. Mar Freshw Res 52:1125-1132

Kareiva PM, Shigesada N (1983) Analyzing insect movement as a correlated random walk. Oecologia 56:234-238

Karnofsky EB, Price HJ (1989) Dominance, territoriality and mating in the lobster, Homarus americanus: a mesocosm study. Mar Behav Physiol 15:101-121 
Karnofsky EB, Atema J, Elgin RH (1989a) Field observations of social behavior, shelter use, and foraging in the lobster, Homarus americanus. Biol Bull 176:239-246

Karnofsky EB, Atema J, Elgin RH (1989b) Natural dynamics of population structure and habitat use of the lobster, Homarus americanus, in a shallow cove. Biol Bull 176:247-256

Koutitonsky VG, Bugden GL (1991) The physical oceanography of the Gulf of St. Lawrence: a review with emphasis on the synoptic variability of the motion. Can Spec Publ Fish Aquat Sci 113

Lawton P, Lavalli KL (1995) Postlarval, juvenile, adolescent, and adult ecology. In: Factor JR (ed) The biology of the lobster, Homarus americanus. Academic Press, New York

Levin SA (1992) The problem of pattern and scale in ecology. Ecology 73:1943-1967

Levin SA, Cohen D, Hastings A (1984) Dispersal strategies in patchy environments. Theor Popul Biol 26:165-191

Loring DH, Nota DJG (1973) Morphology and sediments of the Gulf of St. Lawrence. Bull Fish Res Board Can 182

Millar RB, Anderson MJ (2004) Remedies for pseudoreplication. Fish Res 70:397-407

Miller JM, Crowder LB, Moser ML (1985) Migration and utilization of estuarine nurseries by juvenile fishes: an evolutionary perspective. Contrib Mar Sci Suppl 27:338-352

Moore FR (1980) A modification of the Rayleigh test for vector data. Biometrika 67:175-180

Morales JM, Haydon DT, Friar J, Holsinger KE, Fryxell JM (2004) Extracting more out of relocation data: building movement models as mixtures of random walks. Ecology 85:2436-2445

Petrie B, Drinkwater K, Sandström A, Pettipas R, Gregory D, Gilbert D, Sekhon P (1996) Temperature, salinity and sigma-t atlas for the Gulf of St. Lawrence. Can Tech Rep Hydrogr Ocean Sci 178

Pincock DG, Voegeli FA (2002) Quick course in underwater telemetry systems. Vemco Manual, Shad Bay

Pittman SJ, McAlpine CA (2003) Movements of marine fish

Editorial responsibility: Otto Kinne (Editor-in-Chief), Oldendorf/Luhe, Germany and decapod crustaceans: process, theory, and application. Adv Mar Biol 44:205-294

Royston P (1982) An extension of Shapiro and Wilk's W test for normality to large samples. Appl Stat 31:115-124

Sale PF, Kritzer JP (2003) Determining the extent and spatial scale of population connectivity: decapods and coral reef fishes compared. Fish Res 65:153-172

Schoener TW (1981) An empirically based estimate of home range. Theor Popul Biol 20:281-325

Skalski GT, Gilliam JF (2000) Modeling diffusive spread in a heterogeneous population: a movement study with stream fish. Ecology 81:1685-1700

Speigelhalter DJ, Best NG, Carlin BP, van der Linde A (2002) Bayesian measures of model complexity and fit. J R Stat Soc B 64:583-616

Swihart RK, Slade NA (1985) Testing for independence of observations in animal movements. Ecology 66:1184-1985

Turchin P (1998) Quantitative analysis of movement: measuring and modeling population redistribution in animals and plants. Sinauer Associates, Sunderland, MA

Wahle RA, Steneck RS (1992) Habitat restrictions in early benthic life: experiments on habitat selection and in situ predation with the American lobster. J Exp Mar Biol Ecol 157:91-114

Watson W, Vetrovs HA, Howell WH (1999) Lobster movements in an estuary. Mar Biol 134:65-75

Whitehead H (2001) Analysis of animal movement using opportunistic individual identifications: application to sperm whales. Ecology 82:1417-1432

Wilder DG (1963) Movements, growth and survival of marked and tagged lobsters liberated in Egmont Bay, Prince Edward Island. J Fish Res Board Can 20:305-318

Wolcott TG (1995) New options in physiological and behavioural ecology through multichannel telemetry. J Exp Mar Biol Ecol 193:257-275

Zollner PA, Lima SL (1999) Search strategies for landscapelevel interpatch movements. Ecology 80:1019-1030

Submitted: March 1, 2006; Accepted: July 13, 2006

Proofs received from author(s): January 29, 2007 